\title{
Array-Based Comparative Genome Hybridization in Clinical Genetics
}

\author{
ANAT BAR-SHIRA, GUY ROSNER, SERENA ROSNER, MYRIAM GOLDSTEIN, AND AVI ORR-URTREGER \\ Genetic Institute [A.B-S., G.R., S.R., M.G., A.O-U.], Tel Aviv Sourasky Medical Center, Tel Aviv 64239, Israel; Sackler Faculty of \\ Medicine [M.G., A.O-U.], Tel Aviv University, Tel Aviv 69978, Israel
}

\begin{abstract}
Abnormalities in DNA copy number are frequently found in patients with multiple anomaly syndromes and mental retardation. Array-based comparative genomic hybridization (array$\mathrm{CGH}$ ) is a high-resolution, whole-genome technology that improves detection of submicroscopic aberrations underlying these syndromes. Eight patients with mental disability, multiple congenital anomalies, and dysmorphic features were screened for submicroscopic chromosomal imbalances using the GenoSensor Array 300 Chip. Subtelomeric aberrations previously detected by fluorescence in situ hybridization (FISH) analysis were confirmed in two patients, and accurate diagnosis was provided in two previously undiagnosed complex cases. Microdeletions at 15q11.2-q13 in a newborn with hypotonia, cryptorchidism, and hypopigmentation were detected with few discrepancies between the array results and FISH analysis. Contiguous microdeletion of GSCL, HIRA and TBXI genes at 22q11.2 was identified in a previously undiagnosed boy with an unusual presentation of the VCF/DiGeorge spectrum. In a newborn with aniridia, a borderline false-negative WT1 deletion was observed, most probably because of differences between the size of the genomic deletion and the microarray probe. A false-positive rate of $0.2 \%$ was calculated for clone-by-clone analysis, whereas the per patient false-positive rate was $20 \%$. Array-CGH is a powerful tool for the rapid and accurate detection of genetic disorders associated with copy number abnormalities and can significantly improve clinical genetic diagnosis and care. (Pediatr Res 60: 353-358, 2006)
\end{abstract}

$\mathrm{C}$ hromosomal aberrations frequently underlie multiple anomaly syndromes that include dysmorphic features, learning disability, and growth and developmental delay (1). Standard cytogenetic techniques, such as G banding and SKY (spectral karyotyping), can identify large aberrations including deletions, duplications, amplifications and unbalanced translocations, although their limited resolution makes these tools unreliable for the detection of copy number changes of less than $5 \mathrm{Mb}$ (2). FISH has the advantage of high resolution, but is best suited for the confirmation of known microdeletion and microduplication syndromes in patients presenting with a suggestive phenotype due to the limited number of chromosomal loci that can be simultaneously analyzed.

Array-CGH is an innovative high-resolution technology that detects and maps submicroscopic DNA copy number

Received January 12, 2006; accepted May 10, 2006.

Correspondence: Avi Orr-Urtreger, M.D., Ph.D., Genetic Institute, Tel Aviv Sourasky Medical Center, 6 Weizmann Street, Tel Aviv 64239, Israel; e-mail: aviorr@tasmc. health.gov.il

This work was supported by M.K. Humanitarian Fund.

DOI: 10.1203/01.pdr.0000233012.00447.68 alterations $(3,4)$, improving the diagnostic detection rate of subtle copy number changes. Array-CGH detects quantitative aberrations spanning small regions of the genome, with resolution determined by both the size and the spacing of the clones on the array. CGH-arrays have successfully identified submicroscopic unbalanced chromosomal rearrangements in multiple clinical samples. In three previous studies of patients with mental retardation and dysmorphisms that had normal karyotypes in standard cytogenetic analyses, genomewide arrays have reported rearrangement detection rates of $15 \%$, $24 \%$, and $10 \%$, respectively $(1,2,5)$. Thus, an even higher frequency of rearrangements is expected in the entire population of patients with mental retardation and dysmorphisms. Successful applications also include arrays that focus on particular regions of the genome, including the entire (6-8) and part of (9) chromosome 22, as well as chromosome 1 (10) and the X chromosome (11), and on selected regions known to be associated with genetic disorders and subtelomeric regions $(12,13)$.

Cryptic subtelomeric rearrangements account for approximately $5 \%$ of unexplained mental retardation and/or multiple congenital anomalies (14). Veltman et al. (15) were the first to successfully apply a telomere-specific array-CGH, to confirm known subtelomeric imbalances and to detect additional novel rearrangements in patients with known cytogenetic abnormalities involving one or more telomeres. Additional telomerespecific or whole-genome arrays containing a validated set of human chromosome-specific subtelomere probes have since been developed and successfully applied $(12,13,16)$.

Here we report the implementation of the GenoSensor Array 300 Chip, containing 287 target clones of DNA representing regions of specific genes associated with genetic disorders and subtelomeric regions, for the identification of known and novel submicroscopic alterations in eight children with mental disability, congenital anomalies, and dysmorphic features.

\section{METHODS}

Patients and chromosomal analysis. All cases were referred for consultation to The Genetic Institute, Tel Aviv Sourasky Medical Center and are presented in Table 1. Patients' informed consents were obtained.
Abbreviations: array-CGH, array-based comparative genomic hybridization; BAC, bacterial artificial chromosome; FISH, Fluorescence in situ hybridization; SKY, spectral karyotyping 
Table 1. Medical and genetic evaluation of patients with malformations and mental disability

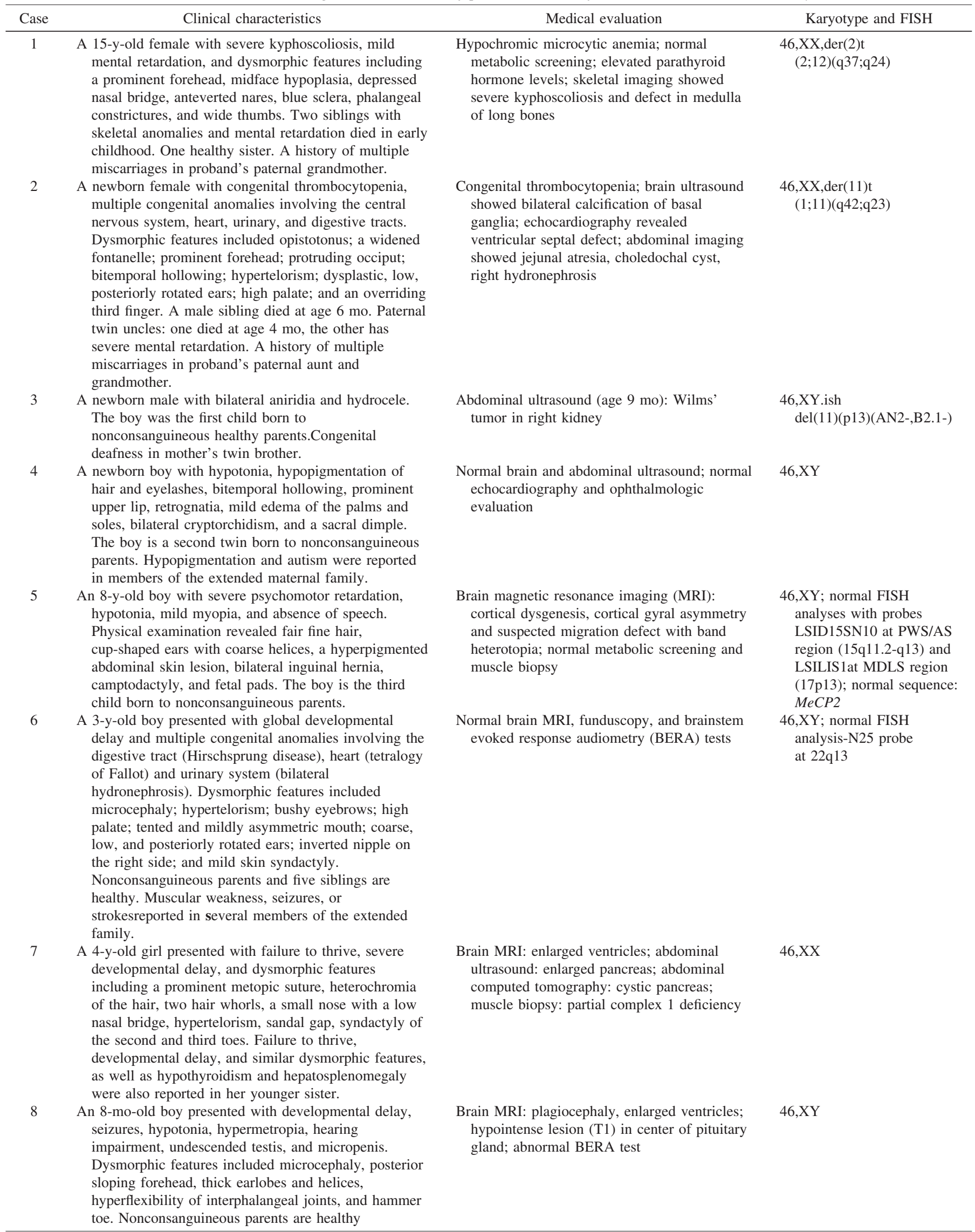


Initial chromosome analysis of peripheral blood leukocytes was performed by standard G-band staining of metaphase chromosomes. Cytogenetic analysis was made according to a standard technique. Karyotypes were established according to the 1995 International System for Human Cytogenetic Nomenclature (17).

FISH analysis. Commercially available probes were used for FISH analyses of the telomeric regions at chromosomes 1q, 2q, and 12q (TelVysion, Abbot Vysis, Chicago, IL), 10q (QBiogene, Illkirch Cedex, France) and 14q (Cytocell, Windsor, CT). Commercially available probes (LSID15S11, SNRPN, GABRB3 and LSID15S10/UBE3A) for the PWS region at 15q11.2q13, TUPLE1 and N25 for the VCF/DiGeorge region at 22q11.2 (Cytocell and Abbot Vysis, respectively), and LSILIS1 for the Miller-Dieker/ Lissencephaly region (Abbot Vysis) were also used for FISH analyses. The following BAC (bacterial artifical chromosome) clones that contain specific gene sequences were used as templates for FISH probes synthesis (Table 2): RPCI11-894C9 for RASSF1 (3q21.3) (M. Rocchi, University of Bari, Bari, Italy), RPCI1-74J1 for WT1 and RPCI11-307I15 for PAX6 (both at 11p13) (CHORI BACPAC Resources, Oakland, California). Cosmid 1p3 for the FLII gene at 11q24 (18) was provided by Dr. Shai Izraeli, and the FISH analysis for the WT1 and PAX6 genes (19) was performed using cosmids B2.1 and AN2, respectively (Dr. Karen Gronskov, personal communication).

BAC or cosmid DNA was extracted using standard protocols. DNA probes were directly labeled by nick translation with Spectrum Orange fluorescent nucleotide (Abbot Vysis) and coprecipitated in the presence of Cot-1 (Abbot Vysis) and salmon sperm DNA (Sigma Chemical Co.-Aldrich, Rehovot, Israel). The chromosome preparation and the fluorescent probes were denatured separately at $73^{\circ} \mathrm{C}$, and probes were allowed to preanneal at $37^{\circ} \mathrm{C}$ before overnight hybridization. Following posthybridization washes, the chromosomes were counterstained with 4',6-diamidino-2-phenylindole (DAPI Vectashield, Vector Laboratories, Burlingame, CA). Hybridization signals were detected using rhodamine and DAPI filters on an Olympus B52 microscope, and the images were captured using a CCD camera and Cytovision Software (Applied Imaging, Santa Clara, CA). For the RASSF1 gene (3q21.3), in addition to FISH hybridization with the entire BAC as a probe, three specific genomic fragments of about $6 \mathrm{~Kb}$ each, representing the $5^{\prime}$, the middle, and the $3^{\prime}$ regions of the gene, were prepared by polymerase chain reaction (PCR), pooled together and labeled for FISH as described. The primers for the specific RASSF1 FISH probes and the PCR conditions are available upon request.

Array-CGH. High molecular weight genomic DNA was extracted from patient's peripheral blood leukocytes using the PureGene DNA Isolation Kit (Gentra Systems, Minneapolis, MN) according to the manufacturer's instructions. Detection of gene copy number was performed by array-CGH using Abbot Vysis GenoSensor system (Abbot Vysis) according to the manufacturer's instructions (Abbot Vysis). Briefly, $100 \mathrm{ng}$ of each test DNA and normal reference DNA (from an individual of the opposite sex of the test sample) was labeled by Random Priming Kit (Abbot Vysis) to incorporate $\mathrm{Cy} 3$ or Cy5 fluorophores (Perkin-Elmer, Boston, MA). DNA was denatured at $100^{\circ} \mathrm{C}$ for $10 \mathrm{~min}$ and was cooled to $4^{\circ} \mathrm{C}$ before the addition of Klenow fragments and nucleotide mix. After incubation at $37^{\circ} \mathrm{C}$ for $2 \mathrm{~h}$, the samples were digested using a 1:20 DNAse dilution for $1 \mathrm{~h}$ at $15^{\circ} \mathrm{C}$. Unincorporated nucleotides were then removed using Sephadex G-50 spin columns (Amersham-Biosciences, Piscataway, NJ). Probes were precipitated with ethanol and resuspended in $10 \mathrm{mmol} / \mathrm{L}$ Tris, $\mathrm{pH}$ 8.0. Equal aliquots of labeled test and reference DNA were combined in a tube with hybridization buffer, denatured at $80^{\circ} \mathrm{C}$ for $10 \mathrm{~min}$, and incubated for $1 \mathrm{~h}$ at $37^{\circ} \mathrm{C}$ to allow blocking of repetitive sequences. The solutions were then hybridized for $72 \mathrm{~h}$ at $37^{\circ} \mathrm{C}$ with a GenoSensor Array 300. This array contains 287 genomic clones, including those for each human telomere, as well as all the known microdeletion syndromes and additional selected loci representing each chromosome arm. The GenoSensor CGH Array 300 clone list is available at http:// www.vysis.com/PDF/GenoSensor300ClonesAndKey_July2004.pdf. After hybridization, the arrays were washed in $50 \%$ formamide $2 \times \mathrm{SSC}$ at $40^{\circ} \mathrm{C}$ and $1 \times$ SSC at $25^{\circ} \mathrm{C}$ and were counterstained with $4^{\prime}, 6$-diamidino-2phenylindole (DAPI). Hybridization signal images in three colors (Cy3, Cy5, and DAPI blue) were then analyzed by the GenoSensor reader system based on DAPI staining that identified target spots and their location on the grid. By analyzing the set of $\mathrm{Cy} 3 / \mathrm{Cy} 5$ ratios (test-to-reference ratios) on all targets, the GenoSensor Array 300 Reader Software (version 1) calculates the ratio most representative of the modal DNA copy number of the sample DNA. For each target the normalized ratio, relative to the modal DNA copy number is calculated. This normalized ratio of the target indicates the degree of gain or

Table 2. FISH and array-CGH results from the analysis of patients with malformations and mental disability

\begin{tabular}{|c|c|c|c|c|}
\hline Case & Previous FISH results & Array-CGH results & $\mathrm{T} / \mathrm{R}$ ratio $\left(p^{*}\right)$ & Validation by FISH \\
\hline \multirow[t]{5}{*}{1} & Gain of 12qtel & Gain of 12qtel & & \\
\hline & 12qtel (CY-LPT-12QG) & U11838 (12qtel) & $1.25(0.005)$ & \\
\hline & Deletion of 2qtel & Deletion of 2qtel & & \\
\hline & 2qtel (CY-LPT-02QG) & WI-6310 (2qtel) & $0.75(0.001)$ & \\
\hline & & D2S447 (2qtel) & $0.73(0.001)$ & \\
\hline \multirow[t]{7}{*}{2} & Gain of 1qtel & Gain of 1qtel & & \\
\hline & D1S3738 (1qter) & 1QTEL10 (1qter) & $1.24(0.001)$ & \\
\hline & $\operatorname{der}(11)+(1: 11)(\mathrm{q}: \mathrm{q})$ & SHGC-1829 (1qter) & $1.29(0.001)$ & \\
\hline & & $\operatorname{AKT3}(1 \mathrm{q} 44)$ & $1.28(0.001)$ & \\
\hline & Deletion of 11qtel & Deletion of 11qtel & & \\
\hline & Fli1 (11q24, 1p3 cosmid) & WI-6509 (11qter) & $0.60(0.001)$ & \\
\hline & & AF240622 (11qter) & $0.59(0.001)$ & \\
\hline \multirow[t]{2}{*}{3} & Deletion of $11 \mathrm{p} 13$ & Deletion of $11 \mathrm{p} 13$ & & Deletion of $11 \mathrm{p} 13$ \\
\hline & $\begin{array}{l}\text { WT1 (B2.1 cosmid) } \\
\text { PAX6 (BAN } 2 \text { cosmid) }\end{array}$ & WT1 & $0.81(0.002)$ & $\begin{array}{l}W T 1 \text { (BAC probe): normal } \\
\text { PAX6 (BAC probe): deleted }\end{array}$ \\
\hline \multirow[t]{5}{*}{4} & Probe from PWS region & Deletion of $15 q 11.2-q 13$ & & Deletion 15q11.2-q13 \\
\hline & $(15 q 11.2-q 13)$ & $S N R P N$ & $0.71(0.001)$ & $S N R P N \pm G A B R B 3$ \\
\hline & LSID15S11-normal & GABRB3 & $0.65(0.001)$ & D15S10/UBE3A1 \\
\hline & & Deletion of 14qtel & & \\
\hline & & IGH (14qtel) & $0.79(0.001)$ & 4qtel: normal \\
\hline \multirow[t]{6}{*}{5} & & Deletion 22q11.2 & & Deletion 22q11.2 \\
\hline & & $G S C L$ & $0.63(0.001)$ & TUPLE1 probe \\
\hline & & $H I R A$ & $0.63(0.001)$ & \\
\hline & & $T B X 1$ & $0.67(0.001)$ & \\
\hline & & Deletion of 10qtel & & \\
\hline & & StSG27915 (10qtel) & $0.77(0.002)$ & 10qtel- normal \\
\hline \multirow[t]{2}{*}{6} & & Deletion of $3 \mathrm{q} 21.3$ & & \\
\hline & & RASSF1 & $0.75(0.002)$ & RASSF1 (BAC probe): normal \\
\hline 7 & & $\mathrm{NCD}$ & & \\
\hline 8 & & NCD & & \\
\hline
\end{tabular}

* $p$ Value calculated by the software

T/R, test-to-reference ratio; NCD, no changes detected, 
loss of copy number, and for each clone the copy number changes are presented. For each target, a $p$ value is calculated automatically by the GenoSensor Array 300 Reader Software (Abbot Vysis), and a $p$ value of $\leq 0.005$ was considered significant.

\section{RESULTS}

We screened eight patients with mental deficiency, multiple congenital anomalies, and dysmorphic features for submicroscopic chromosomal imbalances using array-CGH. All cases were analyzed previously by routine cytogenetic techniques, and chromosomal aberrations were identified in three. CGH results were compared with previous G-banding and FISH analyses to ascertain whether CGH arrays could verify previously detected abnormalities. In the remaining five cases, array-CGH was implemented in an attempt to identify potential submicroscopic rearrangements in complex undiagnosed patients. Each analysis was performed once by an operator with no knowledge of the previous diagnosis. Targets with mean test-to-reference ratios $>1.2$ were considered suggestive of gains, whereas those with ratios $<0.8$ were considered suggestive of losses, in accordance with manufacturer's recommendations (Abbot Vysis) and as previously described $(12,19-21)$. We also performed four "normal versus normal" control experiments and confirmed these threshold values. Our analysis of the normal control samples resulted in a standard deviation (SD) of 0.05 , suggesting that 4 SDs determine the threshold of either gains or losses. Power analysis, assuming an SD of 0.05 among samples and a mean difference of 0.2 between the normal controls and the patients was 0.996 when $n=4$ in each group (Power and Precision Software, Biostat, Englewood, NJ). Gains and/or loss of chromosomal material were detected in six of the eight patients tested (Table 2).

Validation experiments. In two of the three previously diagnosed patients (cases 1 and 2), array-CGH validated the results of FISH and G banding. In case 1, we verified unbalanced $\mathrm{t}(2 ; 12)(\mathrm{q} 37 ; \mathrm{q} 24)$ with trisomy $12 \mathrm{q} 37->\mathrm{qter}$ and monosomy of 2q24->qter. In case 2, we validated the trisomy of 1qtel and the adjacent $A K T$ gene (at 1q44), and the deletion of 11qtel. The latter is compatible with the balanced translocation $\mathrm{t}(1 ; 11)(\mathrm{q} 42 ; \mathrm{q} 23)$ detected in this family.

FISH analysis of case 3 using cosmid probes detected the deletion of one copy of the PAX6 and WT1 genes located at chromosome $11 \mathrm{p} 13$ (22). PAX6 gene is not present on the Array 300, but a T/R ratio of 0.81 and a significant $p$ value of 0.002 were observed for WT1 in the Array 300 analysis of this case (Fig. 1A). Although a few other probes came close to a $\mathrm{T} / \mathrm{R}$ ratio of $0.8(0.81-0.83)$, none of them, except the WTI probe in case 3 , had a significant $p$ value. Therefore, this target was designated as a borderline false negative. Repeated FISH analysis of case 3 with BAC probes for PAX6 and WT1 genes validated the deletion of one copy of the $P A X 6$ gene, but detected two copies of the $W T 1$ gene (Fig. $1 B$ and $C$, respectively), suggesting that the differences in probes' sizes (BAC versus cosmid) determine whether the deletion could unequivocally be detected.

Detection of novel chromosomal aberrations in complex undiagnosed patients. CGH microarray results provided diagnoses in two of the five previously undiagnosed cases. In

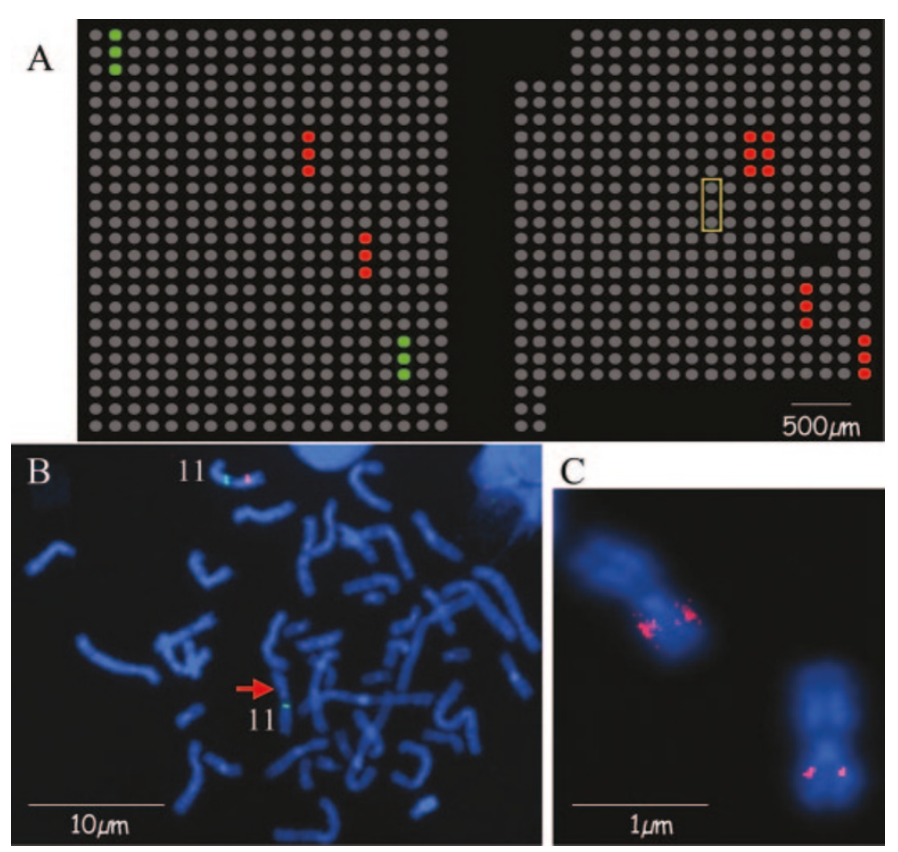

Figure 1. Microarray and FISH analyses of case 3. (A) The array-CGH profile. The $W T 1$ targets are marked in a yellow frame. Because the T/R ratio is 0.81 , the signal is gray and does not appear as a deletion. Male test DNA was hybridized against female reference DNA, resulting in deletion signals of $\mathrm{X}$ chromosome targets (red) and amplification signals of $\mathrm{Y}$ chromosome targets (green). (B) FISH analysis using PAX6 RPCI11-307I15 BAC clone as probe. The red arrow indicates the deletion. (C) FISH analysis using WTI RPCI1-74J1 BAC clone as probe.

case 4, array-CGH analysis showed losses of one copy of two probes in the 15q11.2-q13 region: $S N R P N$ and GABRB3. Four target probes were tested at the Prader-Willi/Angelman region, D15S11 SNRPN, UBE3A and GABRB3, from the centromere to the telomere, using FISH probes and the Array 300 . The probes located at both ends of this region, GABRB3 and D15S11, demonstrated one and two copies of these genes, respectively, using both methods. With the two other probes, there was a discrepancy between the FISH and Array 300 results. Deletion of one UBE3A copy was seen in FISH analysis, but not in the array-CGH. In contrast, deletion of one SNRPN copy was detected in the Array 300 analysis, whereas FISH analysis demonstrated two copies, although one signal was weak, suggesting that one of the breakpoints might have occurred within the SNRPN gene region. Because hypopigmentation was found in this patient, we further suggest that the second deletion breakpoint located distal to the $\mathrm{P}$ locus. Additional microdeletion of one of the subtelomeric clones at the 14qtel was not validated by the FISH analysis.

Case 5 demonstrated contiguous microdeletion of three genes at the 22q11.2 region: GSCL, HIRA, and TBXI. Additional microdeletion of one of the subtelomeric clones at the 10qtel was not detected by FISH analysis.

In case 6, FISH hybridizations using probes of both the entire BAC and specific sequences of this gene did not confirm the deletion of RASSF1 at 3q21.3 detected by the Array 300 , and it was therefore regarded as false positive.

Finally, no abnormalities were detected in the array-CGH analyses of cases 7 and 8 . 


\section{DISCUSSION}

We used array-CGH as an additional tool to resolve undiagnosed complex cases of children with mental deficiency, multiple malformations, and dysmorphic features. The GenoSensor Array 300 chip, containing 287 different probes representing regions significant in cytogenetics or oncology, successfully identified gains and/or losses of DNA copies in five of the eight cases examined.

Results from our array-CGH analyses of cases 1 and 2 correlated well with the rearrangements previously detected by FISH. The array-CGH analysis also detected chromosomal alterations in two previously undiagnosed cases (cases 4 and 5). Microdeletion at the chromosome 15q11-q12 region was detected in case 4 , confirming the suspected clinical diagnosis of Prader-Willi syndrome in the newborn boy. The discrepancies between the Array 300 results and the commercial FISH probe analysis emphasize the importance of specific FISH probes for the validation of microarray data. The combined clinical, FISH, and array-CGH data suggest the breakpoints of this deletion, although the assembly of arrays with high-density clone coverage across the region would allow further definition of the aberration as previously shown for chromosome 22 (6-8), chromosome 1p36 (10), and PraderWilli syndrome region (23), providing more accurate information regarding the genomic breakpoints, the size of the deletions, and the genes involved.

The complex phenotype seen in case 5 was not specific and thus not suggestive of a particular microdeletion syndrome, making diagnosis by classical cytogenetics particularly challenging. Array-CGH detected a microdeletion in the 22q11.2 region, which underlies DiGeorge/velocardiofacial spectrum. However, it is worth noting that the presence of a deletion alone does not necessarily mean that the deletion causes an observed phenotype. The clinical characteristics of case 5 (Table 1) together with the detected deletions of the GSCL, $H I R A$, and TBXI genes, suggest that a larger deletion encompassing additional genes may be involved, affecting the extent of phenotype and disease. Hence, clinical applications of array-CGH will better classify genotype-phenotype correlations.

The use of large insert genomic clones such as BACs for array-CGH provides sufficient signal intensity to quantitatively detect single copy number changes as well as homozygous deletions and high-level amplifications. Additional advantages of larger target probes is the smaller amount of genomic DNA required, less than the amount required for smaller insert (cosmids or oligonucleotides) array platforms. Large inserts can locate the aberration boundaries within the BAC, but when a deletion spans only small region of the BAC, misleading results might be obtained. This is well demonstrated in case 3. The array-CGH profile of this patient did not confirm the previous cytogenetic finding of a deletion of one copy of the WTI gene. The T/R ratio of the WTI gene was 0.81 , within the normal threshold, but interestingly had a significant $p$ value of 0.002 , implying a deletion. This discrepancy is most probably due to differences between the size of the genomic deletion and the probe. The first FISH analysis was performed using a cosmid probe, whereas the second analysis following array-CGH used a larger BAC clone. Presuming that only part of the gene is deleted, a shorter probe compatible to the deletion region would demonstrate the deletion, whereas a larger clone compatible with the entire genomic region identifies the residual gene and thus suggests only a partial deletion. Thus, our data suggest that the large size of the BAC probe may have been the source of the false negative observed here, and because the target DNA amount is usually not limiting, the use of large probes could be a significant disadvantage in any CGH array-based platform.

In addition to the true aberrations identified, three deletions that were suggested by the array-CGH (14qtel in case 4, 10qtel in case 5, and 3q21.3 in case 6) were not confirmed by FISH analysis (Table 2). In cases 4 and 5, only one of the two clones located at the subtelomeric region was altered, whereas the second subtelomeric clone was normal, suggesting that both cases represent a polymorphism rather than a true deletion. These findings are consistent with two recent genomewide screens reporting large-scale polymorphisms in the general population $(24,25)$. Furthermore, copy number changes at 10 qtel were recently detected in normal samples (12), suggesting a DNA sequence length polymorphism at this locus. The third deletion that was not confirmed by FISH (case 6) involved the RASSF 1 gene at $3 \mathrm{q} 21.3$ that was represented as a single target on the array. Repeated analysis of this case on a second array demonstrated two copies of RASSF 1 gene (T/R ratio of 0.83 ), further validating this result as a false positive. Our results suggest that a replicate analysis is advised for clinical samples, but alternatives, such as repeating only the questionable arrays, as suggested by Schaeffer et al. (19), or confirmation by a second method, such as FISH, is also possible. Our data, including these three unconfirmed clones together with the equivocal WT1 gene, suggest a presumed false-positive rate of $0.2 \%$, not substantially different from previously reported false-positive rates of $0.4 \%(15,26)$ and $0.9 \%$ (13). However, taking into account that this study was done in a high-risk population, it is also important to consider the false-positive rate when the number of patients studied is used as the denominator. Of the five patients with deletions, one was false positive, resulting in a relatively high falsepositive rate per patient of $20 \%$. Although the actual falsepositive rate per patient cannot be deduced from our limited sample size, the per-patient false-positive rate should be taken into account when considering any array-CGH as a clinical diagnostic tool.

In summary, using the Array 300 microarray, we identified microdeletions and subtelomeric aberrations in newborns and children with developmental delay and multiple congenital anomalies. Array-CGH offers rapid genomewide analysis at high resolution and provides information directly linked to the physical and genetic maps of the human genome. Although this high-resolution assay will advance the identification of cryptic genomic aberrations underlying human mental retardation and malformation syndromes, it might take some time for the evolution of an advanced platform, combining high accuracy, sensitivity, and specificity with minimal false pos- 
itives and false negatives together with high resolution and lower costs.

The data discussed in this publication have been deposited in NCBI's Gene Expression Omnibus (GEO; http:// www.ncbi.nlm.nih.gov/geo/) and are accessible through GEO Series accession number GSE4775.

Acknowledgments. We thank Abbott Vysis, Inc. for the reagents used in this study and Dr. Karen Gronskov for the FISH analysis with cosmid probes for patient 3.

\section{REFERENCES}

1. Schoumans J, Ruivenkamp C, Holmberg E, Kyllerman M, Anderlid BM, Nordenskjold M 2005 Detection of chromosomal imbalances in children with idiopathic mental retardation by array based comparative genomic hybridisation (array-CGH). J Med Genet 42:699-705

2. Shaw-Smith C, Redon R, Rickman L, Rio M, Willatt L, Fiegler H, Firth $H$, Sanlaville D, Winter R, Colleaux L, Bobrow M, Carter NP 2004 Microarray based comparative genomic hybridisation (array-CGH) detects submicroscopic chromosomal deletions and duplications in patients with learning disability/mental retardation and dysmorphic features. J Med Genet 41:241-248

3. Solinas-Toldo S, Lampel S, Stilgenbauer S, Nickolenko J, Benner A, Dohner H, Cremer T, Lichter P 1997 Matrix-based comparative genomic hybridization: biochips to screen for genomic imbalances. Genes Chromosomes Cancer 20:399-407

4. Pinkel D, Segraves R, Sudar D, Clark S, Poole I, Kowbel D, Collins C, Kuo WL, Chen C, Zhai Y, Dairkee SH, Ljung BM, Gray JW, Albertson DG 1998 High resolution analysis of DNA copy number variation using comparative genomic hybridization to microarrays. Nat Genet 20:207-211

5. Vissers LE, de Vries BB, Osoegawa K, Janssen IM, Feuth T, Choy CO, Straatman H, van der Vliet W, Huys EH, van Rijk A, Smeets D, van Ravenswaaij-Arts CM, Knoers NV, van der Burgt I, de Jong PJ, Brunner HG, van Kessel AG, Schoenmakers EF, Veltman JA 2003 Array-based comparative genomic hybridization for the genomewide detection of submicroscopic chromosomal abnormalities. Am J Hum Genet 73:1261-1270

6. Buckley PG, Mantripragada KK, Benetkiewicz M, Tapia-Paez I, Diaz De Stahl T, Rosenquist M, Ali H, Jarbo C, De Bustos C, Hirvela C, Sinder Wilen B, Fransson I, Thyr C, Johnsson BI, Bruder CE, Menzel U, Hergersberg M, Mandahl N, Blennow E, Wedell A, Beare DM, Collins JE, Dunham I, Albertson D, Pinkel D, Bastian BC, Faruqi AF, Lasken RS, Ichimura K, Collins VP, Dumanski JP 2002 A full-coverage, high-resolution human chromosome 22 genomic microarray for clinical and research applications. Hum Mol Genet 11:3221-3229

7. Erickson RP, Skinner S, Jacquet H, Campion D, Buckley PG, Mantripragada KK, Dumanski JP 2003 Does chromosome 22 have anything to do with sex determination: further studies on a 46, XX,22q11.2 del male. Am J Med Genet A 123:64-67

8. Mantripragada KK, Buckley PG, Benetkiewicz M, De Bustos C, Hirvela C, Jarbo C, Bruder CE, Wensman H, Mathiesen T, Nyberg G, Papi L, Collins VP, Ichimura K, Evans G, Dumanski JP 2003 High-resolution profiling of an $11 \mathrm{Mb}$ segment of human chromosome 22 in sporadic schwannoma using array-CGH. Int $\mathbf{J}$ Oncol 22:615-622

9. Mantripragada KK, Buckley PG, Jarbo C, Menzel U, Dumanski JP 2003 Development of NF2 gene specific, strictly sequence defined diagnostic microarray for deletion detection. J Mol Med 81:443-451
10. Yu W, Ballif BC, Kashork CD, Heilstedt HA, Howard LA, Cai WW, White LD, Liu W, Beaudet AL, Bejjani BA, Shaw CA, Shaffer LG 2003 Development of a comparative genomic hybridization microarray and demonstration of its utility with 25 well-characterized1 p36 deletions. Hum Mol Genet 12:2145-2152

11. Bauters M, Van Esch H, Marynen P, Froyen G 2005 X chromosome array-CGH for the identification of novel X-linked mental retardation genes. Eur J Med Genet 48:263-275

12. Wong A, Lese Martin C, Heretis K, Ruffalo T, Wilber K, King W, Ledbetter DH 2005 Detection and calibration of microdeletions and microduplications by arraybased comparative genomic hybridization and its applicability to clinical genetic testing. Genet Med 7:264-271

13. Cheung SW, Shaw CA, Yu W, Li J, Ou Z, Patel A, Yatsenko SA, Cooper ML, Furman P, Stankiewicz P, Lupski JR, Chinault AC, Beaudet AL 2005 Development and validation of a CGH microarray for clinical cytogenetic diagnosis. Genet Med 7:422-432

14. De Vries BB, Winter R, Schinzel A, van Ravenswaaij-Arts C 2003 Telomeres: a diagnosis at the end of the chromosomes. J Med Genet 40:385-398

15. Veltman JA, Schoenmakers EF, Eussen BH, Janssen I, Merkx G, van Cleef B, van Ravenswaaij CM, Brunner HG, Smeets D, van Kessel AG 2002 High-throughput analysis of subtelomeric chromosome rearrangements by use of array-based comparative genomic hybridization. Am J Hum Genet 70:1269-1276

16. Harada N, Hatchwell E, Okamoto N, Tsukahara M, Kurosawa K, Kawame H, Kondoh T, Ohashi H, Tsukino R, Kondoh Y, Shimokawa O, Ida T, Nagai T, Fukushima Y, Yoshiura K, Niikawa N, Matsumoto N 2004 Subtelomere specific microarray based comparative genomic hybridisation: a rapid detection system for cryptic rearrangements in idiopathic mental retardation. J Med Genet 41:130-136

17. Mitelman F(ed) 1991 ISCN Guidelines for Cancer Cytogenetics, supplement to An International System for Human Cytogenetic Nomenclature. S. Karger, Basel

18. Desmaze C, Brizard F, Turc-Carel C, Melot T, Delattre O, Thomas G, Aurias A 1997 Multiple chromosomal mechanisms generate an EWS/FLI1 or an EWS/ERG fusion gene in Ewing tumors. Cancer Genet Cytogenet 97:12-19

19. Schaeffer AJ, Chung J, Heretis K, Wong A, Ledbetter DH, Lese Martin C 2004 Comparative genomic hybridization-array analysis enhances the detection of aneuploidies and submicroscopic imbalances in spontaneous miscarriages. Am J Hum Genet 74:1168-1174

20. Larrabee PB, Johnson KL, Pestova E, Lucas M, Wilber K, LeShane ES, Tantravahi U, Cowan JM, Bianchi DW 2004 Microarray analysis of cell-free fetal DNA in amniotic fluid: a prenatal molecular karyotype. Am J Hum Genet 75:485-491

21. Le Caignec C, Boceno M, Sougier-Veber P, Jacquemont S, Joubert M, David A, Frebourg T 2005 Detection of genomic imbalances by array based comparative genomic hybridization in fetuses with multiple malformations. J Med Genet 42:121128

22. Gronskov K, Olsen JH, Sand A, Pedersen W, Carlsen N, Bak Jylling AM, Lyngbye T, Brondum-Nielsen K, Rosenberg T 2001 Population-based risk estimates of Wilms tumor in sporadic aniridia. A comprehensive mutation screening procedure of PAX6 identifies $80 \%$ of mutations in aniridia. Hum Genet 109:11-18

23. Klein OD, Cotter PD, Albertson DG, Pinkel D, Tidyman WE, Moore MW, Rauen KA 2004 Prader-Willi syndrome resulting from an unbalanced translocation: characterization by array comparative genomic hybridization. Clin Genet 65:477-482

24. Iafrate AJ, Feuk L, Rivera MN, Listewnik ML, Donahoe PK, Qi Y, Scherer SW, Lee C 2004 Detection of large-scale variation in the human genome. Nat Genet 36:949951

25. Sebat J, Lakshmi B, Troge J, Alexander J, Young J, Lundin P, Maner S, Massa H, Walker M, Chi M, Navin N, Lucito R, Healy J, Hicks J, Ye K, Reiner A, Gilliam TC, Trask B, Patterson N, Zetterberg A, Wigler M 2004 Large-scale copy number polymorphism in the human genome. Science 305:525-528

26. Albertson DG, Pinkel D 2003 Genomic microarrays in human genetic disease and cancer. Hum Mol Genet 12:R145-R152 